\title{
Interim Prosthetic Rehabilitation of a Patient Following Partial Rhinectomy: A Clinical Report
}

\author{
Satyabodh S. Guttal ${ }^{a}$ \\ Paras Vohrab \\ Lekha K. Pillaic \\ Ramesh K.Nadiger ${ }^{d}$
}

\begin{abstract}
Surgical defects often have adverse effects on patient perception of esthetics and self-esteem. Rehabilitation of such surgical defects poses a challenge to the clinician. Presented here is a clinical report of an interim prosthetic rehabilitation of a patient who underwent partial rhinectomy for basal cell carcinoma. Nasal resection included part of the nasal septum, the entire cartilage, and the ala. An interim nasal prosthesis was fabricated for this patient 3 weeks after surgery, to provide early rehabilitation. This prosthesis provided a sociopsychological benefit to the patient, and the prosthesis was well tolerated. The spectacle glasses retained the prosthetic nose. (Eur J Dent 2010;4:482-486)
\end{abstract}

Key words: Nasal prosthesis; Maxillofacial prosthesis; Immediate prosthetic replacement.

\section{INTRODUCTION}

Surgical defects of the midface resulting from malignant disease pose a challenge to patient rehabilitation. Basal cell carcinoma is a cancer that arises in the basal cell layer of the epidermis.

\footnotetext{
associate Professor, Department of Prosthodontics, SDM College of Dental Sciences and Hospital, Sattur Dharwad. Karnataka, India.

b Senior Lecturer, Saraswati Dental College, Lucknow, Uttar Pradesh.

c Professor, Department of Prosthodontics, SDM College of Dental Sciences and Hospital, Sattur Dharwad. Karnataka, India.

d Professor and Head, Chairman for Post Graduate Studies, Chief convener for Dental Technologists Course, Dept. of Prosthodontics, SDM College of Dental Sciences, Dharwad.

- Corresponding author: Dr. Satyabodh S. Guttal Associate Professor, Department of Prosthodontics, SDM College of Dental Sciences and Hospital, Sattur, Dharwad - 580 009, Karnataka, India. Fax: 91-836-2467612 E-mail: drsatyabodhayahoo.co.in
}

Sunlight is a contributing factor in $90 \%$ of the cases. The disease is usually triggered by damage to the skin caused by sunrays.

Basal cell carcinoma of the nasal vestibule is common in Caucasians but rare in blacks and subcontinent Indians. In contrast to one-third of malignancies of non melanoma skin cancer in whites, among Indians, only $1-2 \%$ of these cancers occur in the skin. ${ }^{1}$ Basal cell carcinoma has a particular predilection for the upper central part of the face as an occurrence site. ${ }^{2}$ About $88-90 \%$ of basal cell carcinomas may be seen mainly in sun exposed areas like the face and neck. ${ }^{3}$

Basal cell carcinoma of the nasal area has a high cure rate of more than $95 \%$ but a delay in seeking treatment can allow the cancer to enlarge, causing possible disability. ${ }^{4}$ Treatment of basal cell carcinoma of the nasal vestibule varies, depending on the size, depth, and location of the cancer. Treatment options are surgical removal, 
chemotherapy, and radiation. 5,6 In addition to the conventional treatment methods, other options such as cryosurgery, Mohs micrographically controlled surgery, electrodessication, and photodynamic treatment are also available for head and neck cancers. ${ }^{7}$

Prosthetic rehabilitation of nasal defects after trauma or surgery has been well documented. The sequence of fabrication of an extraoral prosthesis includes a surgical, a provisional, and a definitive prosthesis. ${ }^{8}$ Since an immediate surgical repair of a midface defect is usually not feasible, an interim provisional prosthesis may be considered. This prosthesis can be placed 2 to 3 weeks after the surgery, to provide a cosmetically acceptable appearance. This clinical report describes the use of an interim nasal prosthesis in a patient who underwent partial rhinectomy for basal cell carcinoma. The usage of such an interim or provisional nasal prosthesis permitted the patient to resume social interaction more comfortably and confidently during the healing period and till the definitive prosthesis was fabricated.

\section{CASE REPORT}

A 58-year-old male patient diagnosed with basal cell carcinoma of the nasal vestibule, had undergone partial rhinectomy, and was referred to the department of prosthodontics, SDM college of Dental Sciences, Dharwad, India. Examination revealed that the entire cartilage of the nose, ala, and part of the nasal septum had been resected (Figure 1).

Being a bank employee who regularly addressed customers, the patient expressed deep concern regarding his esthetic appearance. Due to his facial disfigurement, the patient was seeking a solution for his problem soon after the surgery. The patient was not aware of any of such prosthetic rehabilitations; however, when the procedure of provisional nasal prosthesis and its use was explained in detail, he chose to proceed with the treatment.

The boundary for the impression was outlined on the face. Rolled modeling wax was used to confine the impression material (Hindustan Dental Products, Hyderabad, India). Care was taken not to distort the nasal remnants/tissues by blocking out the deep undercuts in the defect with moist gauze. The facial moulage was prepared using an irreversible hydrocolloid material (Algitex, Dental Products of India, Mumbai) (Figure 2). The irreversible hydrocolloid was reinforced with gauze and dental plaster (Everest Brand, Panade Industries Pvt. Ltd., Nippani, Indial. The impression was poured into a Type-III dental stone (Kala Stone, Kala Bhai Pvt. Ltd, Mumbai, Indial (Figure 3).

A nose was sculpted in wax on the resultant cast, using the preoperative photographs. The whole morphology and the anatomic contours of the nose were developed according to normal contours, the patient's own descriptions of his preoperative appearance, as well as the references given by his close relatives. The trial wax pros-

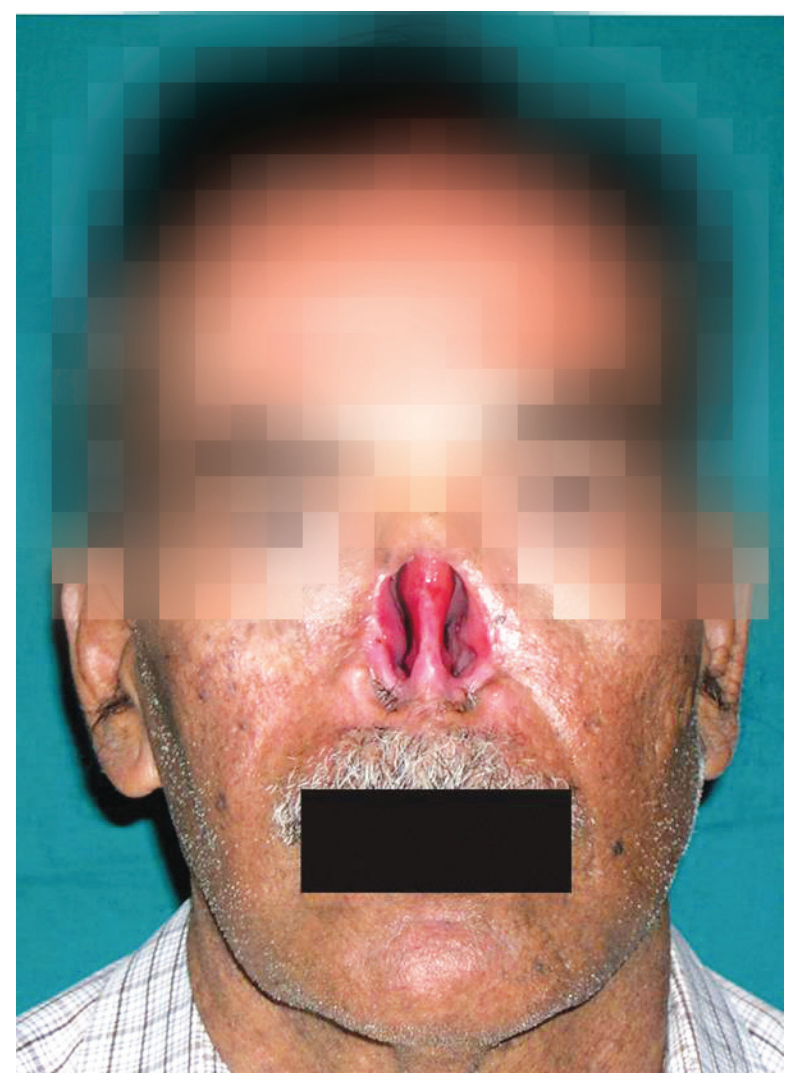

Figure 1. Acquired nasal defect after partial rhinectomy.

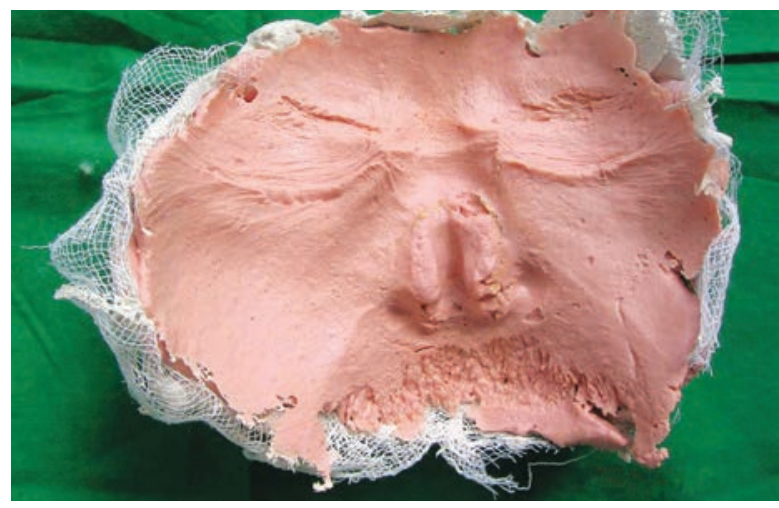

Figure 2. Irreversible hydrocolloid impression of the defect area and the surrounding structures. 


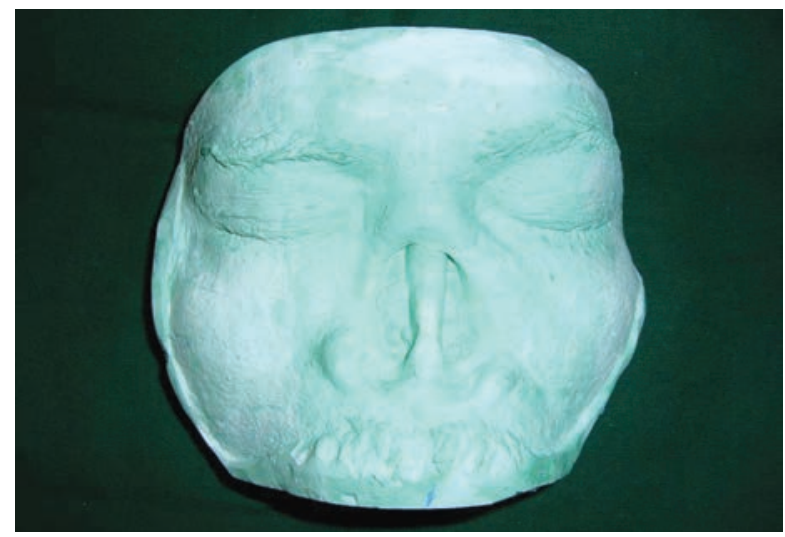

Figure 3. Dental stone cast of the defect.

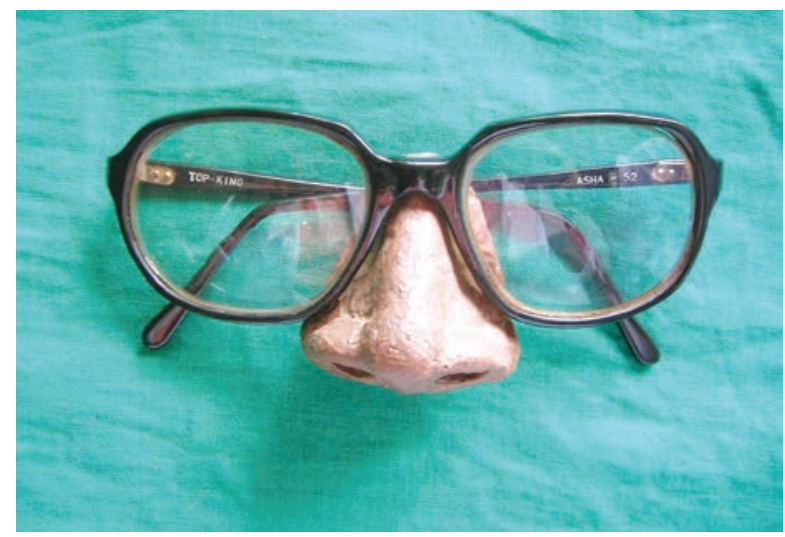

Figure 4. Prosthetic nose attached to the eyeglass frame.

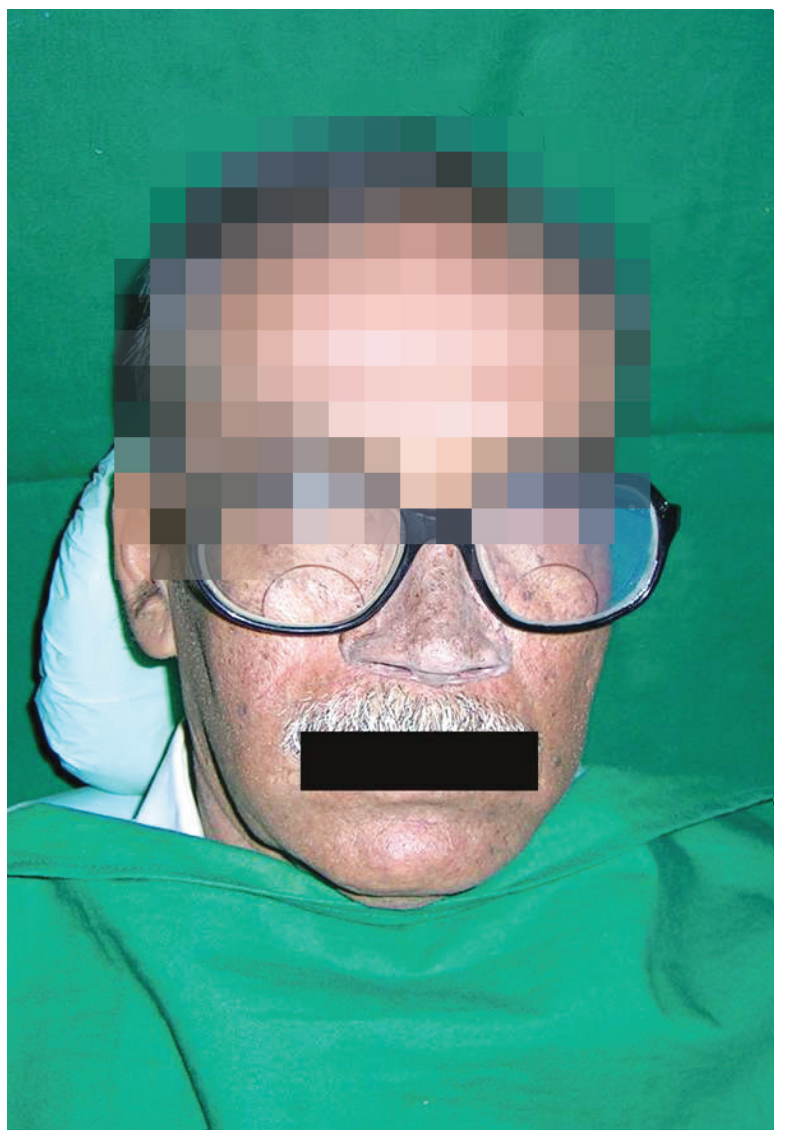

Figure 5. Patient's face with the nasal prosthesis.

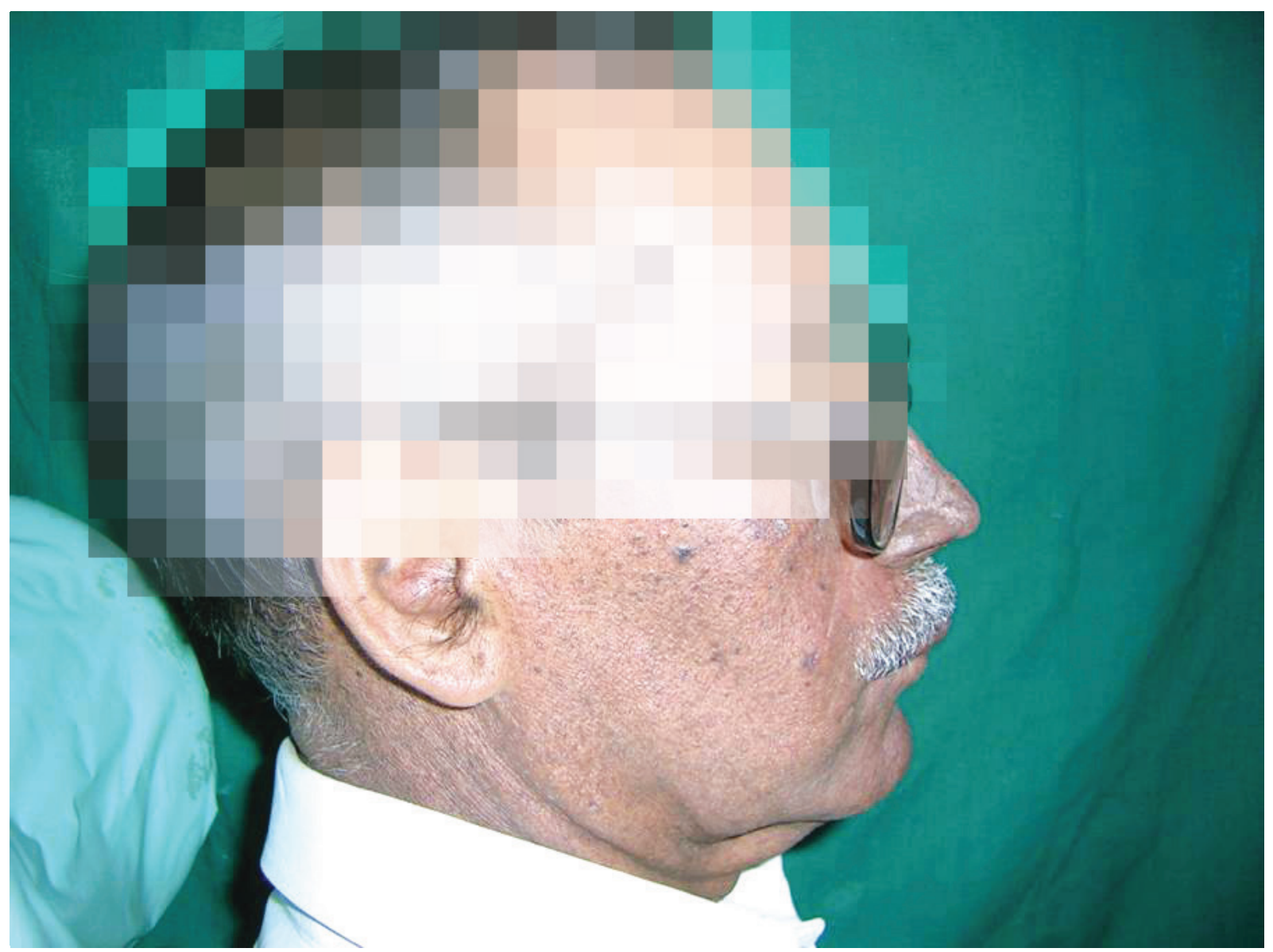

Figure 6. Patient's lateral profile exhibiting the esthetic contours of the nose. 
thesis was completed and the nostril holes were cut open for air exchange. ${ }^{9}$

The margins of the wax prosthesis were finished to create an illusion of continuity with skin. An eyeglass frame was also worn with the wax tryon, anticipating its need for the retention of the final prosthesis. Eyeglasses are a good means of providing retention since they additionally serve to conceal the borders of the prosthesis. ${ }^{10}$

Wax up of the interim nasal prosthesis was invested and the wax boiled out. Heat polymerizing clear acrylic resin was packed and processed. Poly(methyl methacrylate) resin has been recommended as a possible material for use in fabricating a provisional prosthesis. ${ }^{11}$ Intrinsic coloring was incorporated in the clear acrylic resin to match the basic skin tone, using an acrylic-based paint (Fevicryl, Pidilite Industries Ltd, Mumbai, India).

The prosthesis was finished to thin the borders and to blend with the surface of the skin. Thereafter, it was adapted to the defect area. The eyeglass frame and the prosthesis were aligned properly on the bridge of the nose. A cyanoacrylate adhesive (Laborfix; Bracon Ltd, Sussex, England) was used to attach the eyeglass frame to the prosthesis (Figure 4). The patient had small, pigmented dots on the surface of the skin, which was matched by extrinsic coloring using acrylic colors (Fevicryl). This enhanced the esthetics, and the acrylic resin prosthesis resulted in a life-like appearance (Figures 5 and 6). After delivering the prosthesis, home-care instructions were given. The patient returned 2 weeks later for a followup evaluation. Four months later the patient felt that the fit of the prosthesis was not the same as compared to that of the initial placement. It was evident that the fit of the prosthesis had changed accordingly because of the tissue changes occurring during the healing phase. The tissue surface was relined with a soft tissue resilient liner. In addition, at this stage, the preparation of a definitive prosthesis was discussed with the patient. An implant-retained silicone prosthesis was suggested to the patient and the approximate estimation of the treatment time and costs was given. After 6 months of follow-up, the patient is waiting to start using a definitive prosthesis with the option of an implant-retained silicone nose, depending on financial arrangements being made.

\section{DISCUSSION}

Among facial defects, nasal defects produce severe cosmetic impairment, since the nose is a prominent feature of the human face. ${ }^{12}$ Retentive media constitute an important factor for the satisfactory rehabilitation of these defects. In the past, most nasal prostheses were retained with strings or straps anchored behind the head, ${ }^{13}$ intraoral or intranasal extensions, ${ }^{13-15}$ and gold strings or leaves. ${ }^{16,17}$ Spectacle frames have been popular for anchoring nasal prostheses, and preferred even today, when patients express a desire for an economical treatment solution. Today, prosthetic replacements are secured with adhesives that are readily available, easily applied, and provide satisfactory retention for limited periods of time. ${ }^{18}$ However, for an interim nasal prosthesis, spectacle frame retention may be preferred, as was performed in the presented clinical situation. Acrylic resin nasal prosthesis with spectacle retention was a viable treatment provided to the patient. Although resins have shortcomings of being inflexible and having esthetic limitations, for an interim nasal prosthesis, it is an ideal material since it is inexpensive.

\section{REFERENCES}

1. Kumar N, Saxena YK. Two cases of rare presentation of basal cell and squamous cell carcinoma on the hand. Indian J Dermatol Venereol Leprol 2002;68:349-351.

2. Rosso S, Zanetti R, Martinez C. The multicentre south European study 'Helios II': Different sun-exposure pattern in the aetiology of basal cell and squamous cell carcinoma of the skin. Br J Cancer 1996;73:1447-1454.

3. Fink JA, Akerman E. Non melanotic malignant skin tumours of the hand. Hand Clin 1995;11:255-264.

4. Glass LF, Fenske NA, Jaroszeski M. Bleomycin-mediated electro chemotherapy of basal cell carcinoma. J Am Acad Dermatol 1996;34:82-86.

5. McGuirt WF, Thompson JN. Surgical approaches to malignant tumours of the nasal septum. Laryngoscope 1984;94:1045-1049.

6. Thawley SF, Batsakis JG, Lindherg RD, Panje WR, Donley $\mathrm{S}$, editors. Comprehensive management of head and neck tumours. $2^{\text {nd }}$ ed. St. Louis: Elsevier; 1998 p. 526-527.

7. Jacobs $C$, editor. Carcinoma of the head and neck. Boston: Kluwer Academic Publishers; 1990 p. 83-113, 235-237.

8. Marunick MT, Harrison R, Beumer J. Prosthodontic rehabilitation of midfacial defects. J Prosthet Dent 1985;54:553560 . 
9. Brown KE. Fabrication of nose prosthesis. J Prosthet Dent 1971;26:543-554.

10. Miglani DC, Drane JB. Maxillofacial prosthesis and its role as a healing art. J Prosthet Dent 1959;9:159-169.

11. Beumer J, Curtis TA, Marunick MT. Maxillofacial rehabilitation: Prosthodontic and surgical considerations. $2^{\text {nd }}$ ed. St. Louis: Ishiyaku; 1996 p. 404.

12. Breitbart W, Holland J. Psychosocial aspects of head and neck cancer. Semin Oncol 1988;15:61-69.

13. Saunders RCH. The gunner with the silver mask. Am Med Hist 1941;3:283.

14. Kazanjian VH, Rowe AT, Young HA. Prosthesis of the mouth and face. J Dent Res 1932;12:651.

15. Kazanjian VH. Treatment of nasal deformities. J Am Med Assoc 1925;84:177

16. Baird WH. An artificial nose. Dent Cosmos 1905;47:560.

17. Baker L. An artificial nose and palate. Dent Cosmos 1905;47:561.

18. Parel SM. Diminishing dependence on adhesive for retention of facial prosthesis. J Prosthet Dent 1980;43:552-560. 